DigitALCOMMONS @WAYNESTATE-
Michigan Journal of Counseling:

Research, Theory and Practice

Volume 31 | Issue 2

Article 6

$10-1-2003$

\title{
Children, Sports, and Family Dynamics: Are We Having Fun Yet?
}

Patrick J. Morrissette

BrandonUniversity, morris@westman.wave.ca

Roberta Graham

Brandon University

Follow this and additional works at: https://digitalcommons.wayne.edu/mijoc

\section{Recommended Citation}

Morrissette, P. J., \& Graham, R. (2003). Children, Sports, and Family Dynamics: Are We Having Fun Yet?, Dimensions of Counseling, 31(2), 31-37. doi: $10.22237 / \mathrm{mijoc} / 1064966700$

This In the Field is brought to you for free and open access by the Open Access Journals at DigitalCommons@WayneState. It has been accepted for inclusion in Michigan Journal of Counseling: Research, Theory and Practice by an authorized editor of DigitalCommons@WayneState. 


\section{Children, Sports, and Family Dynamics: Are We Having Fun Yet?}

\section{Patrick J. Morrissette}

\section{Roberta Graham}

\section{Brandon University}

Patrick J. Morrissette, Ph.D., NCC, CCC, RMFT is a Professor in the School of Health Studies at Brandon University. Roberta Graham, MMFT is a Lecturer in the School of Health Studies at Brandon University. Correspondence can be directed to the first author at 270 18th Street, Brandon, Manitoba, Canada, R7A 6A9.Emailmorris@westman.wave.ca
The involvement of children in sports is rarely an individual endeavor and can positively and /or negatively affect the entire family system to varying degrees. However, little has been written about how children's participation in sports impact family dynamics. In working toward filling this void, this paper elaborates on several themes that can emerge when children participate in school or community sports. The themes that will be discussed in this paper include: parent/coach/child triangulation, parent coach-parent conflict, performing a dual role, the family all-star, time, financial commitment, and differing parental perspectives. Based on informal observations and discussions with children, parents, and coaches who are involved in a variety of sports, this paper uses case vignettes to augment the discussion.

ncouraging children to remain physically active and involved in sports is an inspiring theme frequently heard throughout society and the media. Whether school or community based, involvement in athleticism in celebrated and is considered an important component of a child's social, mental, physical, and moral development (e.g., Libman, 1998; Roberts, Treasure, \& Hall, 1994; Siegenthaler \& Gonzalez, 1997; Stainback \& La Marche, 1998).

At first glance, the logic behind this societal trend seems sensible and reasonable. Through participation in sports, youngsters encounter opportunities to meet new friends, experience competition, and maintain a physically healthy lifestyle (Chambers, 1991; Klint \& Weiss, 1987; 
Passer, 1982; Wankel \& Kreisel, 1985). Despite these obvious advantages, however, children's participation in sports is rarely consequence-free and can affect family dynamics and / or taint a child's sporting experience. This paper discusses the potential impact that youth sport participation can have on family dynamics. It should be underlined that the intent of this paper is not to portray parents or coaches as culprits in conflictual interactions. Clearly, the majority of parents and coaches are well intended, work toward an enjoyable sporting experience for children, and are unaware of the impact of their behavior.

The themes discussed in this paper are based on direct observation of various interactions before, during, and after sporting events, as well as informal conversations with parents, children, and coaches. While no formal qualitative study was conducted, this preliminary process provided invaluable information upon which to base a future study. Developing a formal study to enhance the credibility of our initial findings will be the next step (Morrissette, 1999). In any case, the themes that emerged out of these informal observations lay the groundwork for further research and discussion. Specific themes that have been extracted from conversations and observations are discussed below with accompanying case vignettes. Pseudonyms have been used to protect the identity of children, parents, and families.

\section{Theme I: Parent/Coach/Child Triangulation}

Although disagreements between parents and coaches are usually resolved through effective communication and negotiation, there are times when conflict persists and children become triangulated between their parents and their coach(es) as depicted in the following vignette. Triangulation involving coach / athlete/ parent has been addressed in the literature (Stainback \& La Marche, 1998; Hellstedt, 1995) and occurs when one member of a conflicted dyad attempts to recruit the support of a third party. A consequence of this interaction typically culminates in a problematic coalition pitting two parties against one.

\section{Case Vignette}

Ten year-old Robin referred to it as the long drive home [italics added]. When his hockey team was doing well, the 15-minute trip home was usually upbeat, cheerful, and uneventful. When his team came up on the losing end of a game, however, the mood in the car would be very different. As one of the better players on his team, Robin would often hear his parents berate his coaches for their poor coaching ability and decisionmaking when Robin's team would lose. As both parents complained, holding the coaches responsible for the team's poor faring, they would often turn to Robin and seek ammunition and support for their criticisms. Robin would often be interrogated about team strategies and coaching behavior. Robin tried different strategies to avoid becoming entangled in his parents' anger without success. Sitting silently and not responding would only provoke his parents to pursue him more tenaciously. Feeble attempts to support his coaches would bring about instant parental disapproval and sarcastic remarks (e.g., You must have been playing in a different game than the one we were watching!). Finally, joining his parents in their criticism seemed the most convenient for Robin despite his feelings of disloyalty, dishonesty, and guilt. He learned that assuming a negative attitude and colluding with his parents would free him from his parents' grip.

Unfortunately, it is not uncommon for children to witness verbal disputes (or even physical altercations) between their parents and their coaches. Although appearing innocuous, children who find themselves in this predicament begin to experience the stress associated with divided loyalties (having to choose one over the other). Metaphorically, parents are in one corner, a coach(s) is in the other, and a child has a foot in each. Needing the approval of their parents, as well as their coach, places children in a very stressful and confusing situation. Children who, unlike their parents, may actually like their coach(s) and appreciate his or her efforts, have described additional stress. These children are reprimanded and their family loyalty questioned if they verbally support or protect their coach. When this scenario develops, it becomes a parent agenda and the needs of children are lost by the wayside. The aforementioned escalation commonly erupts when parents perceive their children as talented athletes whose skills and abilities seem to be overlooked or unappreciated by a coach(s). Unfortunately, children who collude with parents against a coach learn passiveaggressive and non-productive social skills and do not witness effective conflict resolution practices among adults.

\section{Theme Il: Parent Coach-Parent Conflict}

Witnessing one's parent, who is also one's coach, enter into conflicted interaction with teammates and/or parents of teammates can be embarrassing and emotionally troubling for children. Ensuing arguments can frighten and contribute to feelings of insecurity. From these interactions, children observe the inability of adults to appropriately resolve differences as well as hostile behavior, which at its worst, leads to physical threats and / or assault. Siegenthaler and Gonzalez (1997) remarked that children are at the losing end when 
violence and angry disputes occur. According to these authors, children begin to focus less on participation, experience anxiety, and imitate the inappropriate behaviors and attitudes of their parents.

\section{Case Vignette}

Fifteen-year-old Cindy loved soccer and would frequently gather her friends for a friendly pick-up game. When there was a call for coaches for Cindy's four-team league, she immediately convinced and recruited her father. At first, the prospect of having her father as her coach seemed exciting and convenient. Not only would he be on hand to watch her perform at each game but he too, would become immersed in the game. To Cindy's disappointment, some of her teammate's parents began to make snide remarks toward her father during and after matches. Following games, Cindy would often overhear her father argue with a parent over game strategies or how he was trying to fairly divide playing time among his players. Cindy recalled one conversation, in particular, where a mother complained that her child needed more playing time to improve her conditioning. Unbeknownst to the mother however, the youngster was asking for time off the field to recover and rest. To avoid conflict, the youngster avoided disclosing her physical discomfort to her mother. To ensure the child's well-being Cindy's father accommodated the child. Following the match, what began as a civil conversation between the parent and coach ended in a loud shouting match that frightened and embarrassed Cindy. Because she realized that her father was only trying to accommodate a teammate, she felt compelled to support and rescue her father by entering into the argument. Verbally snapping at the mother from over her father's shoulder contributed to mixed feelings of revenge and sadness. Afterwards, Cindy began to feel responsible for her father's obvious frustration since she actively recruited him as a coach.

Wanting to support and protect their parents, children can find themselves entangled in disputes with teammates and parents. Although wellintended, these children transgress a generational boundary and become involved in a matter better settled among adults.

Children report how difficult it is to be teased about having their parent as a coach and / or hear criticism directed toward their parent. In defense of their parent, children are at risk of entering into conflictual interactions with peers and other adults, which can erupt into various forms of verbal and/or physical aggression.

\section{Theme III: Performing a Dual Role}

It is common for parents to be actively recruited or volunteer to coach their children's sports team. Although many benefits are associated with this practice, problems can easily surface and hinder a parent-child relationship.

\section{Case Vignette}

In an effort to fortify an already strong relationship, Mrs. Stevens responded immediately to a call for coaches for her daughter Jane's baseball league. When reading the newspaper ad, she recalled the accolades she received for her athletic prowess as a child and grew increasingly excited about the prospect of contributing to her daughter's success as an athlete. As the season began, Mrs. Stevens looked forward to coaching and enjoyed talking strategy with Jane. To bolster her daughter's skills, Mrs. Stevens began encouraging Jane to "get a jump on the other players" and practice her skills in between team workouts. Before long, Mrs. Stevens had independently designed a rigorous training program organized for Jane and down time after school was converted to skill development. Actual game situations also began to gradually change for Mrs. Stevens and her daughter. With the personalized coaching, Mrs. Steven's expectations and demands on Jane increased. For example, Mrs. Steven's would often remind her daughter that her team was relying on her to "come up big for them" and would be visibly upset when she struck out or made an error on the field. In response to the growing pressure, Jane became fearful of making mistakes and disappointing her mother. To avoid the stress of 
playing under pressure, Jane began to report physical injuries that prevented her from participating. The success of her intervention was a mixed blessing. On the one hand, the stress Jane experienced was dissipating. On the other hand, she missed playing a game she once loved.

On the one hand, becoming involved as a coach affords parents more time with their children and demonstrates commitment. On the other hand, unless this dual role of parent and coach is properly processed within the family, parent-child relationships can be strained. Parents, for example, may have increased expectations for their children, inadvertently show favoritism toward their child, or become excessively demanding of the youngster. Because some parents have grandiose dreams for their children or live vicariously through them (e.g., McPherson \& Brown, 1988), when expectations are not being met they can become frustrated, angry, and harsh with their children. Some parents personalize their child's accomplishments and failures and perceive their child's performance as a direct reflection of themselves.

\section{Theme IV: The Family All Star}

When a child excels at a sport, there is a tendency for parents to encourage continued involved and skill development. For children who excel, this generally translates into increased practice times, competition, and travel. Although beneficial and enjoyable for one child, siblings often find themselves unwilling supporters required to tag along for yet another event that may not be within their interests.

\section{Case Vignette}

Both Alana and her parents were thrilled on learning that she had been selected as a member of the local competitive swim team. Alana had worked very hard to improve her swim times and her efforts were beginning to prove worthwhile. Being on the team meant that Alana would represent her town and travel to tournaments across the country. To celebrate the special occasion, Alana's parents decided to treat her and her younger brother, Matthew, to dinner at their favorite restaurant. While enjoying their dinner, Alana and her parents discussed her accomplishment and spoke with enthusiasm about her elevated status within the community and among her friends. The idea of owning a team jacket and training suit served to heighten Alana's excitement. Although Alana and her parents were elated, Matthew was less than thrilled with the prospect of having to get up early for what he considered boring trips and long days. The notion of watching people swim was not Matthew's idea of having a good time. As Matthew complained about the sacrifices he would have to make for his sister, Alana became increasingly angry. What began as a celebration dinner soon turned into an unpleasant family outing.

One solution for some parents in this dilemma is to arrange for childcare or appropriate supervision while they are away with the family athlete. There are several consequences associated with this decision. For example, families find themselves frequently apart and disjointed. Second, attention may be focused on one child. Third, family expenses skyrocket when considering the costs associated with travel, accommodations, meals, competition fees, additional child care, and so forth.

Resentment can grow with siblings who feel that their needs or accomplishments are secondary and overlooked. Offspring who receive less attention describe a sense of family abandonment and begin to perceive their accomplishments as inferior and meaningless.

The pressure experienced by children who are recipients of extra attention and family resources can also be overwhelming. Realizing that their family is making major sacrifices on their behalf, these young athletes experience worry, increased anxiety and pressure to perform. Other children who sense elevated status within their families might challenge parental authority, test family boundaries, and become embroiled in family conflict.

Parents also learn that with a child's athletic success comes increased recognition and status within the parental group and community. Seduced by the increased status, parents can push their children to succeed in order to maintain center stage and an elevated sense of self.

\section{Parental Expectations and the Pressure Experienced by Children}

The desire to simply have fun is sometimes dashed for children when they discover that their parents are more interested in seeing them win. Dreams of their child as an elite athlete begin to influence how parents participate with their children. Rather than encouraging their child, parents begin to point out mistakes and criticize their effort, commitment, and skills. Some parents, for example, can be heard calling out disparaging remarks to their children as they play or are seen scolding their children for what they perceive to be a lackluster performance (Siegenthaler \& Gonzalez, 1997). When this occurs, children have to contend with their own disappointment as well as parental criticism. Rather than appreciating a youngster's willingness to try, parents end up imposing unrealistic expectations on children (Coakley, 1993). 
Young athletes may be bribed by their parents. For instance, children may be tantalized with money, a new piece of equipment, or extended privileges if they perform at a certain level. Rather than reinforcing effort, social skills, and life skills, parental focus is placed squarely on a superior performance and winning. At this juncture, it is important to realize that parents who behave in this manner are not necessarily malicious or negligent. Rather, they have succumbed to a competitive force.

\section{Theme V: Time and Financial Commitment}

\section{Case Vignette}

Sam eagerly anticipated youth karate registration. He wanted to meet new friends and learn exciting moves as observed in action films. Finally registration day arrived and as promised, his father accompanied Sam to his first class. Because Sam's karate lessons overlapped with his sister's piano lessons, Sam's father was responsible for getting both children to and from their respective activities on time. Although Sam's father anticipated a tight schedule he was confident that he could successfully meet the needs of both his children. Although the first couple of weeks went smoothly, Sam was beginning to sense his father's displeasure about having to "race all over town" to accommodate his children's activities. When Sam's father would arrive to pick Sam up from his karate class, he would appear irritated and would holler out commands for Sam to get changed. Embarrassed and unable to properly say goodbye to his friends and coaches, Sam would rush to meet his father. Conversations between Sam and his father initially revolved around the fun he was having with instructors and friends. Over time, however, their conversations drifted toward complaints about becoming a chauffeur to his children's activities. To pacify his father, Sam would sit silently and often regret that he joined karate.

Parents who actively support and attend their children's sporting events frequently remark on the enormous time and financial commitment that is required. Sometimes parents are caught off guard when expenses mount and financial resources dwindle. Coaches and/or other parents are quick to remind them of the value associated with extra practice time and competition. Parents reluctantly succumb to feelings of guilt and forge ahead. A covert message some children begin to receive from parents pertains to the expected dividends from their emotional and financial commitment. In concrete terms, parents who devote substantial emotional and financial resources expect their children to progress and perform at high levels.

\section{Impact of Family Lifestyles}

Parents and children in pursuit of athletic excellence soon realize that their lives quickly center on the sporting event. To accommodate the activity, daily schedules and routines are adjusted and personal interests are begrudgingly suspended. Because changes in practice and game times are common, families can experience stress when attempting to meet schedule demands. Parents describe their hectic lives as burning the candle at both ends [italics added]. This scenario can intensify for families with more than one child participating in athletic activities. As they spend more time travelling between events, matter better settled among adults. rather than actually watching their children play, parents arrive at events appearing frazzled and disgruntled. To remain on schedule, these parents can be heard barking out orders to their children in the locker room to quickly change and pack their gear. With little time to socialize with their peers, or thank a coach(s) for his or her time and effort, children are swiftly shuffled from the event. Although well-intended, it becomes clear that the stress experienced by these parents contributes to their overall fatigue and strained relationships with their children. Rather than sports being an enjoyable and relaxing family outing, athletic events begin to symbolize chaos and distress.

\section{Theme Vl: Differing Parental Perspectives}

\section{Case Vignette}

The Friday evening Junior High School evening basketball game was a popular event for students, players, and the community. Kevin dreamed of the day when he would represent his school in front of his peers, community, and family. Neither of his parents had played organized sports but nevertheless, encouraged his participation. To Kevin's delight, both his parents began to actively follow his team's standing and would get excited when game night approached. Over dinner they would chat about 
the ability of various players and team progress. Initially, the conversations Kevin had with his parents were light and free flowing. In a short period of time, however, the conversational tone changed and an obvious difference of opinion between his parents surfaced. As a way of encouraging his son and his team's success, Kevin's father supported a more aggressive style of play. In contrast to her husband, Kevin's mother openly criticized her husband's position and discouraged aggressive play. What started out as friendly family discussions, soon changed to heated arguments between parents. The situation escalated to a point where Kevin's mother refused to attend his games, fearing injury to her son.

Conflict within family relationships can emerge when there is a disagreement between parents regarding the primary purpose of athletic participation. For example, parents do not always share the same competitive spirit and quarrel over their child's effort or performance. Likewise, not all children and parents agree on the purpose of sport. Some parents perceive sport as a training ground to learn about the harsh realities of the world (e.g., fierce competition, only the fittest survive attitude) (e.g., Sage, 1978) whereas their children simply want to exercise and socialize with friends. One parent may encourage aggressive competition, while the other adamantly opposes this form of behavior. These differing perspectives can create tension between parents and inadvertently triangulate children.

When parents fail to reach a mutual agreement regarding the meaning they personally attribute to their child's participation in sports, they remain locked in disagreement. Unfortunately, in an effort to remain loyal to each parent and avoid the conflict, children can begin to feel pulled in two directions. In an attempt to resolve the situation, some children simply withdraw from the sport.

\section{Role of the Counselor}

Counselors can provide direct clinical service, education, and/or consultation when assisting children, families, and athletic organizations. In terms of direct service, counselors can work with children and their families to discuss the impact of sport activity. During this process, ounselors can

also educate

parents and athletic

organizations

regarding potential

factors that can

impact children,

families, and

coaches. When

ulfilling the role as

educator, counselors

can encourage

parents and coaches

to reflect and

monitor their own

behavior. counselors can remind family members that individual needs may not always be met. Explaining the difficulty of accommodating everyone's preferences and the value of encouraging a sibling during a practice or game becomes necessary for effective family functioning. Working toward establishing reciprocal and caring relationships reduces the potential for competition between siblings and struggles for parental time.

Furthermore, when coaching one's own children, parents must balance supportive parenting and motivational coaching. Performing this dual role requires ongoing communication with one's own child, his or her teammates, and parents. Openly expressing the challenges inherent in this dual role while inviting feedback and support can make the task much easier and enjoyable for everyone involved.

Counselors can also educate parents and athletic organizations regarding potential factors that can impact children, families, and coaches. When fulfilling the role as educator, counselors can encourage parents and coaches to reflect and monitor their own behavior. Taking time to think about one's underlying intentions and behavior, and their potential implications, can reduce the occurrence of unfortunate situations. This process may be especially useful for adults who are former athletes or who perceive themselves as highly competitive.

Finally, counselors can serve as consultants to athletic organizations and help in developing mission statements, guidelines, and codes of conduct. By assuming a metaposition, counselors can maintain a broader perspective and consider the needs of children, families, coaches, and organizations.

\section{Conclusion}

Based on personal observations, informal conversations with children, parents and coaches, it appears that there is no single factor that contributes to a negative family experience regarding youth sport participation. In short, each family situation and experience is unique. Despite ongoing reminders to parents, children, and coaches about the fundamental purpose of sport participation, unanticipated events and interactions have the potential to negatively impact families.

It comes as no surprise that an effective way to prevent or reduce unnecessary conflict is to encourage ongoing 
reflection and communication. Jeopardizing relationships with children, spouses, young athletes, parents, and coaches, for the sake of winning is simply a no-win proposition. Only through self-monitoring strategies and effective communication can parents and parent-coaches monitor the process and the relationships affected by their involvement.

\section{References}

Chambers, S. (1991). Factors affecting elementary school students' participation in sports. The Elementary School Journal, 91, 413-419.

Coakley, J. (1993). Social dimension of intensive training and participation in youth sports. In B. B. R. Cahill, \& A J. Pearl (Eds.), Intensive participation in youth sports (pp. 77-94). Champaign, Il: Human Kinetics.

Hellstedt, J. (1987). The coach/parent/athlete relationship. The Sport Psychologist, 1, 151-160.

Klint, K., \& Weiss, M. (1987). Perceived competence and motives for participating in youth sports: A test of Harter's competence motivation theory. Journal of Sport Psychology, 9, 55-65.

Libman, S. (1998). Adult participation in youth sports. Child and Adolescent Psychiatric Clinics of North America, 7, 725-744.
McPherson, B., \& Brown, B. (1988). The structure, processes, and consequences of sport for children. In F. L. Smoll, R. A. Magill, \& M J. Ash (Eds.), Children in sport (pp. 265-286). Champaign, Il.: Human Kinetics.

Morrissette, P. (1999). Phenomenological data analysis: A proposed model for counsellors. Guidance and Counselling, 15, 2-7.

Passer, M. (1982). Children in sport: Participation motives and psychological stress. Quest, 33, 271-285.

Roberts, G., Treasure, D., \& Hall, H. (1994). Parental goal orientations and beliefs about the competitive-sport experience of their child. Journal of Applied Social Psychology, 24, 631-645.

Sage, G. (1978). Psychosocial implications of youth sports programs. Arena Review, 2, 18-23.

Siegenthaler, K., \& Gonzalez, G. (1997). Youth sports as serious leisure: A critique. Journal of Sport and Social Issues, 21, 298-317.

Stainback, R. \& La Marche, J. (1998). Family systems issues affecting athletic performance in youth. The Psychotherapy Patient, 10, 5-20.

Wankel, L., \& Kreisel, P. (1985). Factors underlying enjoyment of youth sports: Sport and age group considerations. Journal of Sport Psychology, 7, 51-64. 